\title{
Infestation of Ectoparasites in Dairy Calves Reared by Smallholder Farmers in Central Areas of Ethiopia
}

\author{
Beksisa Urge*, Markos Tadele and Tamirat Siyoum \\ Ethiopian Institute of Agricultural research, Holeta Research center, Ethiopia \\ *Corresponding author: Beksisa Urge, Ethiopian Institute of Agricultural research, Holeta Research center, Ethiopia
}

ARTICLE INFO

Received: 陆 March 03, 2020

Published: March 10, 2020

Citation: Beksisa U, Markos T, Tamirat S. Infestation of Ectoparasites in Dairy Calves Reared by Smallholder Farmers in Central Areas of Ethiopia. Biomed J Sci \& Tech Res 26(3)-2020. BJSTR. MS.ID.004360.

Keywords: Calves; Ectoparasite; Ethiopia; GIT helminthes; Infestation; Risk Factors

\section{ABSTRACT}

Ectoparasites are one of the major health constraints of cattle production and are usually associated with huge economic losses in Ethiopia. A cross-sectional and clinical investigation was carried out in urban and periurban dairy farms in different central areas of Ethiopia to determine the infestation of external parasites and its attributable risk factors in dairy calves. Thus, a total of 157 dairy calves were clinically examined for ectoparasite infestations in central Oromiya. Results from data analysis indicated that from a total examined calves for ectoprasites, $40.76 \%(64=101)$ were found to be infested with one or more parasites and the major ectoparasites identified were Ambyloma species (3.8\%), Boophilus species (5.7\%), Lice species (17.2\%) and mixed infestations (8.9\%). Furthermore, the risk factor analysis showed that the proportion of ectoparasites was relatively higher in cross breed (48.9\%) than in local breed of calves (35.1\%).but, there was no significant difference $(\mathrm{p}>0.05)$ in harboring either single or mixed parasites between the breed of calves and sex category showed a significant variation. It was also found that calves reared under semi-intensive (73.5\%) management system were more vulnerable to infestation than calves managed intensively (25.9\%) and the seasonal infestation showed higher infestation rate in wet season (42\%) than in dry season (38.6\%). Hence, season of the year and management system significantly influenced the infestation of ectoparasite in dairy calves. The findings of the present study lead to the conclusion that parasites are one of the major health problems of calves in the study area demanding urgent control interventions.

\section{Introduction}

Veterinary ectoparasites commonly tick, mites, lice and ked have a significant impact on the health, wellbeing and productivity of animals. They play an important role in the transmission of certain pathogens [1] and they are known to cause heavy economic losses to livestock industry [2]. Among ecto-parasites, ticks have been recognized as the notorious threat due to severe irritation, allergy and toxicosis and in some cases, ticks have been reported to cause lowered productivity and mortality [3] and transmit diseases such as babesiosis, theileriosis, anaplasmosis [4]. Ticks act not only as potential vectors but also as reservoirs of certain infectious agents e.g. Pasteurella multocida, Brucella abortus and Salmonella typhimurium in man and animals [5]. Besides ticks, lice also cause harm in cattle health. Lice infestation keeps animals in poor physical condition and develops an unthrifty, anemic appearance and discolored greasy hair [6]. Louse free animals have been reported to be more profitable than infested animals due to increased rate of weight gain and more feed utilization.

In addition, lice infestation contributes to huge economic losses due to damage to skin and hide in the form of light flecks and spots followed by secondary bacterial infection or scratching behavior and inflammation of the skin Furthermore, ectoparasitic mites cause a mange in a wide range of domestic and wild vertebrate hosts including man [7]. On the other hand, a considerable economic negative impact associated with mange infection is due to extensive skin damage and morbidity and mortality of infested animals. Mites classified as borrowing and none borrowing and affecting animals by causing a considerable damage on skin and wool are 
economically important on livestock [8], So that due to the above explanation on the negative impact of ectoparasites on health, production and productivity as well as lack of studies on their epidemiology and the effect of associated risk factors on calf, the current study is supposed to be extremely mandatory to generate significant information that would help to mitigate parasite related losses in the study areas, Therefore, the objectives of the present study were

a) To determine the species of external parasites of dairy calves and putative risk factors

b) To determine the infestation rate of calf ecto-parasites and recommend possible control and prevention packages

\section{Materials and Methods}

\section{Study Areas}

The study was carried out in Muka turi, Grar Jarso and Degem in North West shewa zones of the oromiya region situated in the central high lands of Ethiopia. The area is located between 78 and $150 \mathrm{~km}$ northwest of the capital, Addis Ababa and lies on an elevated plateau that ranges from 2400 to $3500 \mathrm{~m}$ above sea level and receives the mean annual rainfall with the mean annual maximum and minimum temperature of $1000-1500 \mathrm{~mm}$ and with the mean minimum and maximum temperature of $15-18^{\circ} \mathrm{C}$ respectively. The study area also included Adea berga and welmera districts of west shewa zone which are located in the central highlands of Ethiopia. Ada'a berga is one of the districts in west shewa zone and situated in central highlands of Ethiopia $30 \mathrm{~km}$ away from Holeta and the rainfall pattern of the district is bimodal, and the long rainy season extends from June to September. The farming system of the area is mixed type where crop production and livestock rearing are done side by side. Welmera district is $40 \mathrm{~km}$ away from the capital city, Addis Ababa and area is situated at 9004'- 9013' N latitude and 38029'-38039' E longitude. The average altitude of the area ranges from 2200-2500 m above sea level. It receives an average annual rainfall of $1060 \mathrm{~mm}$. The mean maximum and minimum temperatures are $23.3^{\circ} \mathrm{C}$ and $4.6^{\circ} \mathrm{C}$ respectively.

\section{Study Dairy Calves and Design}

The study was conducted on dairy calves kept under the different management systems. All local and cross breed calves and not treated with anthelmintic drugs were sampled in each farm in respective of sex, body condition and other relevant parameters. A cross sectional study design and clinical examinations were applied to study external parasites of calves during the wet and dry seasons of the year.

\section{Sampling Techniques and Sample Size Determination}

Purposive sampling method was used to select infested dairy calves from each district. Study calves with no history of anthelmintic treatment were included in the study. Accordingly, 157 dairy calves were sampled for the investigation of ectoparasite infestation.

\section{Sample Collection and Laboratory Investigations}

Collection and Identification of External Parasites from Infested Dairy Calves: Clinically infested calves were examined by close inspection, palpation and parting the hairs against their natural direction for easy detection of external parasites. Ectoparasites were collected from different parts of the body of the individual calves by hand picking. Small hairbrush dipped in ethanol was used for collection of ticks. The site of attachment was smeared with ethanol and proper precautions were taken to preserve the mouthparts and appendages of the ectoparasites during collection. Then ectoparasites were immediately preserved in $70 \%$ alcohol in clean glass vials and labeled accordingly. Skin samples were also collected from clinically infested calves for mange mites according to the procedure given by $[8,9]$. The morphology of ectoparasites was studied in the laboratory with the help of dissecting (4X) and compound (10X) microscope. All collected ectoparasites were examined and identified according to the identification keys and descriptions given by Shearer $[9,10]$.

Data Analysis: All data collected from the study area were coded and entered into Microsoft Excel spreadsheet 2007 computer program and analyzed using Statistical Package for Social Science (SPSS)-Version 19 or 20 and SAS 2004. Descriptive statistics and percentage was calculated to display the status of parasites in relative to considered variables. The association between the effects of variables such as breed, sex, age and infestation was analyzed using the Pearson chi-square $(\chi 2)$ test. The Odds Ratio (OR) was also used to assess the strength of association between variables with the helminthes infection and prevalence of parasites. In all cases, p-value less than 0.05 held at $95 \%$ confidence intervals was considered for significance level.

\section{Results}

Out of the total dairy calves $(n=157)$ examined for ectoparasite infestation in the central areas, 64 of them were infested with one or more species of parasites and the overall prevalence was $40.76 \%$. From the total infested calves, 3.8\%, 5.7\%, 5.1\% and 17.2\% were accounted for Ambyloma species, Boophilus species, Feas and Lice species respectively. Moreover, mixed infestations were also recorded with the proportion of $8.9 \%$ (Table 1 ).

An overall percentage of $40.76 \%$ ectoparasites in dairy calf were recorded using clinical examination techniques (Table 2). The present study revealed that the proportion of ectoparasite was relatively higher in cross breed (48.9\%) than in local breed of calves (35.1\%). similarly, the proportion in male and female calves was (54.5\%) and (33.3\%) respectively. However, there was no significant disparity in harboring external parasites between 
season and breed of calves ( $p>0.05)$. The study also implied that ectoparasitic infestation was higher $(73.5 \%)$ in calves managed under semi intensive management system than those managed under intensive management system (25.9\%). Likewise, the higher infestation rate was observed in wet season (42\%) than in dry season (38.6\%). Nonetheless, statistically insignificance variation was detected ( $p>0.05)$ (Table3). Analysis of the risk factors revealed that the prevalence of external parasite in male calves was significantly varied among sex groups $(\mathrm{P}<0.05)$ indicating that male calves were more likely to be infested than female calves. Calves managed under semi intensive management was more likely to be infested by various parasites than those calves kept under the intensive management conditions (Table 4).

Table 1: Infestation rate of ectoparasites in dairy calves.

\begin{tabular}{|c|c|c|c|}
\hline \multirow{2}{*}{ Ectoparasites encountered } & \multicolumn{3}{|c|}{ Examined Dairy Calves (n=157) } \\
\cline { 2 - 4 } & Total infested \\
Calves & 6 & Proportion (\%) & 95\% CI \\
\hline Ambyloma species & 9 & 3.8 & $0.80-4.77$ \\
\hline Boophilus species & 8 & 5.7 & $2.40-5.80$ \\
\hline Fleas & 27 & 5.1 & $1.59-6.01$ \\
\hline Lice species & 14 & 17.2 & $5.70-7.21$ \\
\hline Mixed infestations & 64 & 8.9 & $2.80-10.03$ \\
\hline Overall infestation & 40.76 & $32.1-51.27$ \\
\hline
\end{tabular}

Table 2: Proportion of external parasite infestation in dairy calves.

\begin{tabular}{|c|c|c|c|}
\hline \multirow{2}{*}{ Study areas } & \multirow{2}{*}{$\mathbf{N}$} & \multicolumn{2}{|c|}{ Infestation status } \\
\cline { 3 - 4 } & & Not infested (\%) & Infested (\%) \\
\hline Central Oromia & 157 & $83(52.86)$ & $64(40.76)$ \\
\hline Overall proportion & & & 40.76 \\
\hline
\end{tabular}

Table 3: Infestation of Ectoparasites in relation to different risk factors $(n=157)$.

\begin{tabular}{|c|c|c|c|c|}
\hline Variables observed & No of examined Calves & Infested calves (\%) & Chi square & p-value \\
\hline \multicolumn{5}{|c|}{ Breed } \\
\hline cross & 90 & $44(48.9)$ & & \\
\hline local & 57 & $20(35.1)$ & 0.065 & 0.41 \\
\hline Total & 157 & $64(40.8)$ & & \\
\hline \multicolumn{5}{|c|}{ Sex } \\
\hline female & 102 & $34(33.3)$ & & \\
\hline male & 55 & $30(54.5)$ & 2.26 & 0.016 \\
\hline Total & 157 & $64(40.8)$ & & \\
\hline \multicolumn{5}{|c|}{ Management System } \\
\hline intensive & 108 & $28(25.9)$ & & \\
\hline semi-intensive & 49 & $36(73.5)$ & 10.67 & 0.019 \\
\hline Total & 157 & $64(40.8)$ & & \\
\hline \multicolumn{5}{|c|}{ Season } \\
\hline Wet & 100 & $42(42.0)$ & & 0.21 \\
\hline Dry & 57 & $22(38.6)$ & 0.08 & \\
\hline Total & 157 & $64(40.8)$ & & \\
\hline
\end{tabular}

Table 4: Logistic regression analysis of risk factors in relation to ectoparasites infestation.

\begin{tabular}{|c|c|c|c|c|}
\hline Variables & No examined & Calves Infested (\%) & Odd ratios for $95 \% \mathrm{CI}$ & p-value \\
\hline \multicolumn{5}{|c|}{ Sex of Calves } \\
\hline female & 102 & 33.3 & $0.23(0.22-.0 .4)$ & \\
\hline male & 55 & 54.5 & $2.1(0.35-0.55)$ & 0.016 \\
\hline Total & 157 & 40.8 & & \\
\hline
\end{tabular}




\begin{tabular}{|c|c|c|c|c|}
\hline \multicolumn{5}{|c|}{ Management System } \\
\hline intensive & 108 & 25.9 & 1 & 0.019 \\
\hline semi-intensive & 49 & 73.5 & $3.1(0.26-0.41)$ & \\
\hline Total & 157 & 40.8 & & \\
\hline
\end{tabular}

\section{Discussion}

The results of the present investigation indicated that the overall prevalence of ectoparasites of dairy calves was $40.76 \%$.This finding was higher than the reports of $[11,12]$ who reported $32.8 \%$ and $21.28 \%$ respectively but lower than the reports of [13] who reported $46.15 \%$ in and around Bishoftu, Adama and Bangladesh respectively. This difference in the prevalence of ectoparasite might be due to the presence of various factors like animal husbandry practice, feeding and management, veterinary service delivery system and variation in the geographical locations.In the current study, the prevalence of lice infestation on calf was about $17.2 \%$. This finding was relatively higher when compared to the reports of [12] (9.5\%) and lower than the reports of [14] who reported $21.6 \%$ prevalence on calves in Nabeul in north east Tunisia. The current finding was also comparable with the reports of [12] (9.5\%) but lower than the reports of [14] (2013) and [11,15] who reported $21.6 \%$ and $69.2 \%$ and $26.8 \%$ on calves in regions of Nabeul in North-East Tunisia and in Southern alberta in Canada and in and around Bishoftu Ethiopia respectively.

The higher prevalence of lice on calves in this study might be due to the indoor and outdoor keeping nature of calves in different areas, poor grooming behavior, lack of awareness about the effect of lice on calves, and other health problems. It was also found that Ambyloma species (3.8\%), Flea species (5.1\%), Boophilus species $(5.7 \%)$ and mixed infestations $(8.9 \%)$ were the most identified ectoparasites at the study areas. This result was comparable with the reports of [11] who reported that Ambyloma species accounted for (7.6\%) and Boophilus species accounted for $(5.2 \%)$ as well as [16]. Boophilus decoloratus and Ambyloma species were dominant in this animal in Benchi maji zone south west and central Ethiopia respectively [17]. Furthermore, the study revealed that the prevalence of ectoparasites was relatively higher in cross breed calves (48.9\%) than in local breed (35.1\%). similarly, the prevalence in male and female calves was (54.5\%) and (33.3\%) respectively. however, the difference in the prevalence was not statistically significant $(p>0.05)$ between the breed but significant between the sex of calves.

This finding was similar with the reports of [12] who reported that the difference in the prevalence of external parasite was not statistically significant $(p>0.05)$ between the breed of calves. Further investigation revealed that calves reared under semiintensive $(73.5 \%)$ management system were more vulnerable to ectoparasitic infestation than those managed intensively (25.9\%). It was statistically significant $(\mathrm{p}<0.05)$. This report is similar to the finding of [11] who reported, the highest ectoparasitic infestation like lice in extensive management system (45.14\%) followed by in semi-intensive system (32.35\%) and intensive system (20.57\%). Other authors such as [18] found that lice infestation was significantly higher in extensive production system than in intensive production system. This could be due to the poor management systems applied and early release of calves to the pasture and in adequate veterinary service delivery system in semi intensive management system might exacerbate the condition. The dam might have been in contact with animals from other herds at communal grazing and serve as a source of infestation to the calves.

On the other hand, [11] reported that the prevalence of ectoparasitic infestation was significantly $(\mathrm{p}<0.01)$ higher in local breed of calves $(39.3 \%)$ than in cross breed (23.22\%), as well as in male calves $(33.3 \%)$ than in female calves $(32.4 \%)$ but the same in case of lice infestation in male (27\%) and female (26\%) in and around Bishoftu. This higher prevalence in cross breed of calves (48.9\%) might be due to the fact that cross breeds are more vulnerable than local breed of calves to ectoparasites. since, cross breed that are kept under free grazing system are not afforded well and lesser emphasis given by the owners on management of these animals. This was in line with the findings of [12] and [13] who reported a positive correlation between lice and animal breed. The result also showed that calves were more susceptible to ectoparasites infestation in wet (42\%) season than dry season (38.6\%). Found the highest number of ectoparasites like ticks occur during the rainy season. The seasonal prevalence of ectoparasites particularly tick infestation is significantly high during the rainy (24.33\%) and summer seasons $(21.58 \%)$ as compared to the winter season (4.03\%). This Variation in prevalence could be attributed to differences in agro-ecology, sampling season and animal management system.

\section{Conclusion and Recommendations}

The present study revealed that the prevalence of external parasite in all age groups of calf at the study area is mainly due to non-adoption of recommended prophylactic measures and related management practices. It is highly recommended that appropriate prophylactic measures such as spraying and dipping technologies should be used and awareness creation should be adopted for farmers. Future studies should take into account the economic impacts of these parasites and the drug resistance patterns to formulate better therapeutic strategies and alternative measures to be applicable in the study districts.

\section{References}

1. Loomis EC (1986) Ectoparasites of cattle. Vet Clin North America 2(2): 299-321. 
2. Branscheid W, Schroer (1997) Damage to cattle hides, detection, frequency and economic importance. Fleischwirtschaft (77): 333-337.

3. Niyonzema A, Kiltz HH (1986) Control of ticks and tick-borne diseases in Burundi. Australian Center for International Agricultural Research (17): 16-17.

4. Norval RAI, Fivaz BH, Lawrence JA, Brown AF (1984) Epidemiology of tick-borne diseases of cattle in Zimbabwe. Tropical Animal Health and Production 17(1): 19-28.

5. Jongejan F, Uilenberg G (2004) The global importance of ticks. Parasitology 129: S3-S14.

6. Nelson WA (1984) Effects of nutrition on animals on their ectoparasites. J Med Entomol 21(6): 621-635.

7. Nafstad O, Gronstol H (2001) Variation in the level of grain defect light flecks and spots on cattle hides. Acta Vet Scan 42(1): 91-98.

8. Urquhart GM, J Armour, JL Duncan, AM Dunn, Jennings FW (1996) Veterinary parasitology2, University of Oxford, Long man scientific. The high and technical press, UK, pp. 100-109.

9. Soulsby EJI (1982) Helminths, Arthropod and Protozoa of Domesticated Animals. ( $7^{\text {th }}$ Edn.), Bailliere, Tindall and Cassell Ltd, 136-346, 365-491 and 763-778.

10. Shearer D (1997) Veterinary Entomology. (1 ${ }^{\text {st }}$ Edn.), Chapman and Hall. London, UK, 265 and 290.

\section{ISSN: 2574-1241}

DOI: $10.26717 /$ BJSTR.2020.26.004360

Beksisa Urge. Biomed J Sci \& Tech Res

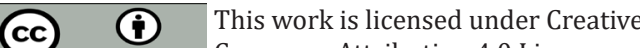

Submission Link: https://biomedres.us/submit-manuscript.php
11. Assefa K, Hika W, Tayu D (2014) Prevalence of Major Ectoparasites of calves and associated risk factors in and around Bishoftu town. African Journal of Agricultural research 10(10): 1127-1135.

12. Yacob HT, Netsanet B, Dinka A (2008) Prevalence of Major skin disease in cattle, sheep and goat at Adama veterinary clinic oromiya regional state, Ethiopia. AAU Ethiopia Rev Med Vet (159): 455-461.

13. Bilkis MF, Mondal MMH, Rony SA, Islam MA, Bengun N (2011) Host determinant-based prevalence of ticks and lice in cattle (Bosindicus) at Borga district of Bangladesh, progress. Agric 22(1-2): 65-73.

14. Gharbi M, Abdallah BH, Mbarek Y, Jedid M, Dargouth MA (2013) Crosssectional study of cattle lice infestation in the region of Nabeul in northeast Tunisisa. Rev Sci Tech off Int Epiz 32(3): 1-8.

15. Colwell DB, Bill C, Calvin WB, Timothy GF, Kee JG, et al. (2001) Prevalence of sucking and chewing lice on cattle entering feedlots in southern Alberta. Can Vet J 42(4): 281-285.

16. Onu SH, Shiferaw TZ (2013) Prevalence of ectoparasite infestations of cattle in Bench Maji zone, southwest Ethiopia. Veterinary World 6(6): 291-294.

17. MEKONNEN S, HUSSEIN I, BEDANE B (2001) The distribution of ixodid ticks (Acari: Ixodidae) in central Ethiopia. Onderstepoort Journal of Veterinary Research 68(4): 243-251.

18. Nigatu K, Teshome F (2012) Population Dynamics of cattle ectoparasites in western Amhara National regional state. Ethiopia J vet med Anim Health (4): 22-26.

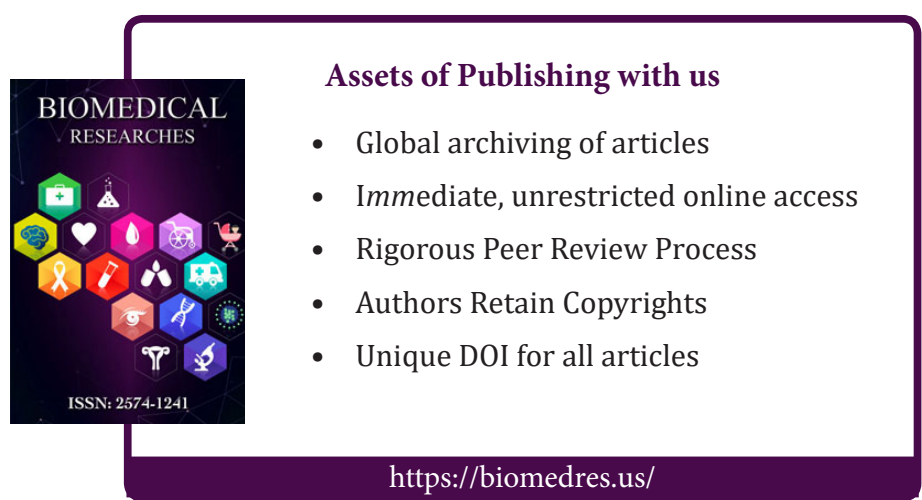

